\title{
JUSTIFICACIONES EXTRA-LITERARIAS DEL CUENTO EN LA ENSEÑANZA PRIMARIA ${ }^{1}$
}

\begin{abstract}
Resumen
Antes de la Renovación curricular, en las Guías para el maestro que el Ministerio de Educación Nacional entregaba a los docentes, se justificaba la literatura en la enseñanza primaria de dos maneras. No obstante, ambas formas remiten la literatura a aspectos exteriores a ella misma: de un lado, a asuntos distantes de su especificidad artística (tales como apoyar los contenidos de otras asignaturas, despertar sentimientos patrióticos y formar moralmente); $y$, de otro lado, a asuntos que si bien apuntan a su especificidad (tales como la materialidad lingüística de la literatura y la pregunta por el efecto estético), no obstante, son planteados de una manera que la escamoten
\end{abstract}

Palabras clave: Justificación extra-literaria, cuento, enseñanza primaria, literatura, lenguaje.

\begin{abstract}
Before the Renovation curricular, in the Guides for the teacher that the Ministry of National Education surrendered to the educational ones, the literature was justified in the primary teaching in two ways: Nevertheless, both forms remit the literature to aspects external to herself: of a side, to distant matters of their artistic specificity (such as supporting the contents of other subjects, to wake up patriotic feelings and to form morally); and, of another side, to matters that although they point for you specify (such as the linguistic materiality of the literature and the question for the aesthetic effect), nevertheless, they are outlined in a way that the hide.
\end{abstract}

Key words: Curricular renovation, literature, primary teaching, teacher.

\footnotetext{
* Profesor Universidad Pedagógica Nacional. E-mail: bustama@colnodo.apc.org

1 El presente artículo resume las dos primeras partes del informe de la investigación titulada "Concepción del Ministerio de Educación Nacional sobre la literatura y su enseñanza en primaria $\left(1^{\circ}\right.$ a $\left.3^{\circ}\right)$, antes de la Renovación curricular", que realicé en la Uni-
}

El MEN justifica² de dos formas genéricas la existencia de la literatura

versidad Pedagógica Nacional durante 1996. Este artículo fue recibido el 15 de octubre de 2003 y aprobado el 31 de octubre de 2003. en la enseñanza primaria; ambas pueden denominarse "extra-lite-

\footnotetext{
2 Afirmarlo en tiempo pasado podría hacer suponer que las posiciones descritas ya han sido abandonadas, asunto que habría que demostrar.
} 
rarias", pues remiten el cuento a aspectos que están por fuera de él. En la primera parte, se tratarán las justificaciones extra-literarias que podrían denominarse "ilegítimas" (desde el punto de vista de la especificidad de la literatura), como son otras asignaturas, el concepto "patria" y el moralismo. En la segunda parte, se considerarán las justificaciones extra-literarias "legítimas", o sea, que apuntan a aspectos pertinentes, como el lenguaje (forma material de la literatura) y lo estético (una de sus características); pero que, no obstante, son planteadas de manera contraproducente.

\section{Justificaciones extra-literarias "ilegítimas"}

\subsection{Otras asignaturas}

Para el MEN, se justifica el cuento como objeto de la enseñanza primaria por el hecho de que existen las demás asignaturas, y no por él mismo: "La narración es un medio eficaz para interesar a los niños en las diversas materias del programa escolar" (3a:51) ${ }^{3}$. Más adelante, plantea que los cuentos de la Naturaleza ( $\left.3^{\circ} a: 53\right)$ : "Ilustran hábitos de los animales, leyes de la naturaleza, crecimiento de las plantas, formación de la tierra, estimulan el interés y amplían los conocimientos". Para primero, dice: "En cada semana, los temas afines se han integrado alrededor de un tema central que corresponde unas veces al área de Estudios Sociales, y otras, al de Ciencias Naturales" (1ํa:4); y, de ahí en adelante, todos los cuentos trabajados, o que se sugieren, giran en torno al tema central de la semana.

3 Como se citan frecuentemente los textos del MEN, se reseña únicamente el curso, utilizando el cardinal $\left(1^{\circ}, 2^{\circ}\right.$ y $\left.3^{\circ}\right)$. En los casos de $1^{\circ}$ y $3^{\circ}$, se agrega una letra, que indica el primero o segundo textos del MEN reseñados para ese grado en la bibliografía. Después de los dos puntos, se coloca el número de la página de donde se saca la cita; si nada antecede a los dos puntos es porque se trata del mismo texto reseñado inmediatamente antes.
Por ejemplo, cuando se trata de hablar de las propiedades de los alimentos, en el programa de segundo $\left(2^{\circ}: 27\right)$, se recurre a coplas como la siguiente:

\section{Si hortalizas comemos de las verdes y amarillas mejores ojos tendremos para leer la cartilla.}

Se presupone la necesidad de que existan las "diversas materias del programa escolar"; en cambio, la literatura requiere una justificación explícita que el MEN busca en otras asignaturas. Es notoria una falta de equilibrio en esta consideración, pues en ningún documento del MEN se plantea que las demás asignaturas del programa escolar se justifiquen por la existencia de la literatura; tampoco se dice que sirvan para explicar la existencia del cuento, ni aun para incentivar a los niños hacia el arte. Por lo tanto, en esta función asignada a los cuentos están implícitos: a) una jerarquización, según la cual las verdades históricas y naturales serían primarias, mientras que las artes serían secundarias; y b) un desconocimiento de la especificidad de la literatura.

Contribuyen a considerar secundaria a la literatura los criterios de "eficacia" (la primera cita dice que la narración es un medio eficaz para interesar en las otras asignaturas), "utilidad" y "aplicabilidad"; se nos ha enseñado a pensar que "lo que se hace debe servir para algo"; principio que aparece y rige en una sociedad que tiene estipulado un precio para cada cosa, incluso para el arte; una sociedad que desde sus comienzos ha ejercido la idea de que "El tiempo es oro"; y que ahora, en los tiempos neoliberales, ha tomado la forma de una evaluación de las acciones humanas desde los criterios de eficiencia y eficacia.

De esta forma, si todo tiene precio, si lo que se hace debe ser aplicable, entonces el cuento, al menos, debe interesar a los niños en otras asignaturas que sí sirven, estimular el interés y ampliar los conocimientos, como dicen las citas. Dar al arte tanta importancia como a las asignaturas consideradas imprescindibles, pone en riesgo el futuro en una sociedad del lucro, la acumulación, la prisa y la eficacia. El principal papel "asignado" por los procesos históricos a los maestros -capacitar para el desempeño económico y la articulación en lo social-, en cierta medida riñe con la formación del niño en algunas áreas culturales. De ahí que éstas aparezcan con el fin de afianzar otras consideradas más útiles.

A nivel de la sociedad en su conjunto sucede algo parecido: se crean condiciones adversas a lo cultural, se producen conceptualizaciones superficiales y se trata de educar en tal sentido; sin embargo, se alaban las obras (Gioconda, Quinta Sinfonía, Don Quijote) a condición de que su potencia transformadora se "museifique", se recicle en los procesos ideológicos de la sociedad, ingrese en una escala de valores y reconocimientos ajena al arte mismo.

Esta concepción está lejos incluso de lo que se pensaba hace 24 siglos; Aristóteles decía que hay prácticas con interés social, tales como el comercio, la técnica y la educación; y prácticas desinteresadas, tales como el arte, la filosofía y la ciencia, cuya especificidad no está definida por la obtención de un resultado inmediato y medido por el éxito. Por el contrario, estas prácticas culturales "tienen una función social múltiple, que en último término es la de creación de cultura con una racionalidad, un método, una perspectiva y una función social. Es decir, todo el saber en general tiene una 'utilidad' histórica en cuanto transforma los modos de pensar y de vivir" (Londoño, 1989:72).

Claro está que, además de trabajar sobre el cuento, se puede hablar de otras asignaturas; y es obvio que se necesita hacerlo, pues el arte es interpretado desde prácticas cultu- 


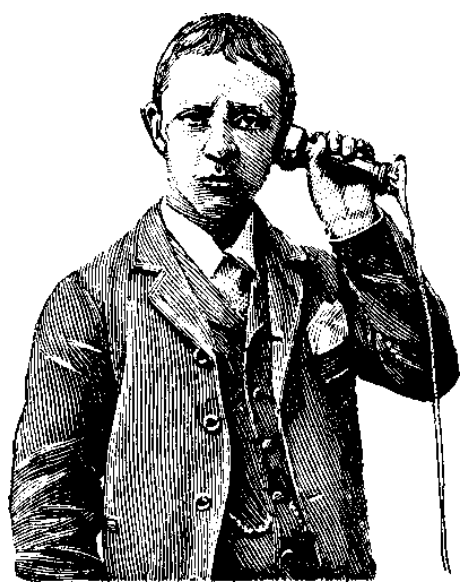

rales concretas, además de ser él mismo intertextual. Pero esto exige, de una parte, el respeto de su especificidad y, de otra, una forma de trabajo que no prive al niño del hecho de que el saber humano no viene dividido en las "asignaturas" del currículo escolar, ni se ha producido así.

Además, valdría la pena preguntarse si se le está haciendo un favor a las otras asignaturas cuando los textos que se privilegian no tienen una lógica argumentativa. El cuento se usa más con el sentido de una "motivación"; se piensa que el niño no tiene el nivel para asumir discursos argumentativos y que, en consecuencia, hay que animarlo con historias (supuestamente más cercanas a su nivel de desarrollo) para, de todas formas, "entregarle" un saber que debe aprender, pero que no está en capacidad de comprender; es decir, una clara perspectiva heteroestructurante (Not, 1994).

En el cuento En los tiempos de la conquista, por ejemplo, el personaje-maestra, "para aprovechar el gran interés de los alumnos", hace una lectura sobre la llegada de los españoles; terminada la lectura, los personajes-alumnos preguntan, como si se supieran el libreto-currículo de memoria: " ¿Trajeron los españoles a sus esposas? [...] ¿Qué enseñaron los españoles a los indios? [...] ¿cuánto tiempo manda- ron aquí los españoles? [...] ¿qué productos trajeron los conquistadores? [...] ¿Cómo se llamaron los primeros españoles que pisaron nuestras tierras?" (3ํำ:111).

Las respuestas que los personajes dan a estas preguntas, se supone, constituyen datos del currículo del área; pues bien, algunas de éstas son las siguientes imprecisiones históricas: que, en un principio, los españoles no trajeron a sus esposas porque estaban acostumbrados a ciertas comodidades que no podían disfrutar en estas tierras; y que los españoles les enseñaron a los indios a hablar su propio idioma, su religión y sus costumbres. Formas muy curiosas de hablar del saqueo y de la imposición por la violencia.

Igual pasa, en tercero, con los cuentos Conversación con la abuelita, a propósito de los medios de transporte (3ำ:125); De compras con mis amigos, para hablar del comercio (:140); El tesoro de los niños, a propósito de las carteleras (:146); Elecciones en la escuela, para referirse a los mecanismos de representación política (:155); y La historia de Ricardo, a propósito de la salud (:185). $Y$ en segundo, con los cuentos La ranita verde y el ganso, para hablar de las ranas en la agricultura (2o:76); Declaración de la Independencia, en el que los personajes-estudiantes, emocionados por la clase de sociales, vuelven y representan los hechos que precedieron la petición de Cabildo Abierto, relato que se usa para "precisar los acontecimientos sobresalientes del grito de Independencia" (:92); El cafeto, cuento idéntico a la descripción de la historia del café en clase de sociales, pero narrado en primera persona (:121); y La sal y otros minerales, cuento en el que el niñopersonaje pregunta por el contenido de ciencias naturales y su padre, como un buen profesor, suple el currículo de la semana número 28 de la programación (:130).

Si no hubiera ciencias sociales y naturales, no habría necesidad del cuento; ni siquiera habría cuentos: "Aun cuando los cuentos, fábulas, leyendas y anécdotas pueden relatarse en forma ocasional, conviene incluirlos además dentro del período de lenguaje oral, especialmente cuando los temas de estudios sociales y ciencias naturales, lo requieran" (3ํa:55).

No obstante, la especificidad del arte está lejana de la utilidad. Kant, por ejemplo, para definir el juicio estético, excluye lo que no le es esencial; $y$, entre varios factores, excluye la utilidad (Londoño, 1990:148): el arte no puede entenderse desde un punto de vista practicista, en el sentido de "servir para hacer algo". Por ser un producto humano, es una finalidad, pero no tiene fin, objetivo externo a él mismo; puede tener finalidades políticas, religiosas, etc., pero éstas no lo definen. Frente a la idea de entregar un saber teórico -como quiere el MEN- el arte "no pretende ofrecer una descripción de algo en la forma de una aseveración; no intenta explicar nada. No es una sustitución de la ciencia ni ocupa su lugar" (Londoño, 1990:149).

Concepciones y recomendaciones del MEN, como las que se vienen comentando, hacen que la división en asignaturas, de origen metodológico, así como la supuesta jerarquía entre ellas, lleguen a pensarse como constitutivas del saber o de los objetos. La "integración" de asignaturas no se lleva a cabo en la educación primaria como determinada por una característica del saber, sino por una supuesta poca capacidad intelectual del niño; la prueba es que, a medida que asciende por la escala de los cursos, se le fracciona con más severidad el saber.

\subsection{El patriotismo}

EI MEN también justifica la literatura en la primaria con ayuda de otro criterio extra-literario "ilegítimo": la Patria. Así, asigna al maestro la labor de "Procurar que los niños conozcan de preferencia la poesía, la literatura y el folklore de su país y 
luego los de otros países para que aprecien y comparen los valores artísticos propios" (3a:51).

La urgencia del MEN por inculcar esta noción es comprensible, pues la educación, en cualquier país del mundo, trata de mantener las condiciones existentes, y éstas requieren la idea de "patria". No obstante, siendo que se plantea que al comienzo habría que privilegiar nuestros valores artísticos, mucha de la literatura citada no es colombiana ${ }^{4}$ : en primero, la hay de Italia ( $19 \mathrm{~b}: 24)$, México (:43), Argentina (:82, 104), Grecia (:50, 137); en segundo, la hay de Paraguay (:39), Chile (:80, 132), Arabia (:127), Puerto Rico (:142), Costa Rica (:146), México (:157); y, en tercero, la hay de Cuba (3o:16), Rusia (:58), México (:70), España $(: 74)$, Costa Rica $(: 126,149,150) \ldots$ En este caso, afortunadamente, el MEN ni siquiera es ejemplo de lo que promulga.

La noción de "patria" tiene origen en el replanteamiento de algunos principios, como la nobleza y la divinidad, que llevó consigo el triunfo de la burguesía y la implantación del capitalismo. Las funciones ideológicas -que durante el feudalismo corrían fundamentalmente a cargo de la iglesia-fueron disgregadas en un conjunto de prácticas sociales que también acogieron a la divinidad, pero en forma de un séquito de semi-dioses: Progreso, Justicia, Libertad, Civilización, Humanidad, Patria, etc. (Lafargue, 1973:56-57). Acorde con la función que tenía el otro dios, ahora parcialmente desterrado, se pretendió que estos semi-dioses existían por sí mismos, autosuficientes, eternos, omnipotentes y que engendraban los fenómenos históricos.

${ }^{4}$ Los textos oficiales anteriores a la Renovación Curricular son muy inconsistentes: en muchos relatos y poesías no vienen reseñados los autores; entre los reseñados, no todos tienen su nacionalidad; los datos sólo a veces mencionan los textos de donde son sacados; etc.
Como ejemplo, baste señalar la importancia de la idea de "libertad" para la aparición de una fuerza de trabajo que ahora ya no se encontraba ligada a los medios de producción, ni al nivel de su propiedad ni al del control del proceso productivo: de siervos que no podían ser desarraigados de su tierra y que tenían cierta autonomía sobre la producción, se pasa a obreros "libres", es decir, con su fuerza de trabajo como única posesión, "libres" de venderla o no, o sea, de morir o no de hambre. Tal vez no sea pertinente explicar aquí la inconsistencia de creer que ideas como patria, libertad, civilización, etc. son eternas, autosuficientes y omnipotentes; basta señalar que, al hablar de la cultura, la noción "patria" resulta imprecisa, ya que:

a. La literatura no refleja las condiciones que la rodean, como se podría inferir de la cita del MEN. La sociedad constituye las condiciones dentro de las cuales se da la literatura; por lo tanto, ésta responde a las características de aquélla. No se pueden separar la Ilíada y la Odisea de la navegación griega, del comercio de la época, de sus dioses, de las

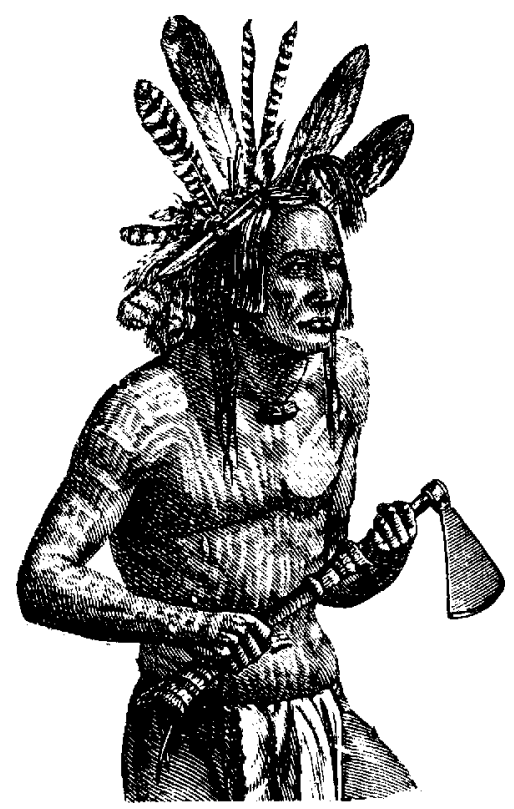

técnicas de guerra hasta entonces desarrolladas, de la geografía del mundo antiguo, etc. Pero esos hechos no son los que dan valor artístico a esas obras, puesto que hoy, en una sociedad con economía, técnicas y divinidades distintas, todavía nos conmueven. Zuleta (1986) plantea que Kant, Marx y Freud señalaron esta "transhistoricidad" del arte como una clave de su especificidad. EI arte no puede abstraerse de su contexto, pero no es un documento histórico, geográfico o natural. Para decirlo en términos de Barthes (1978:23), la literatura asume y toma a su cargo muchos saberes, es el fulgor mismo de lo real; pero lo real no puede ser representado; en ello consiste una de sus funciones: la función utópica. Si la literatura tiene algo de universal, de transhistórico, es justamente porque está constituída por algo más que la expresión de sus condiciones; forma parte de las relaciones objetivas y subjetivas de una sociedad y está condicionada por ellas.

b. La internacionalización de las estructuras económicas hace que las relaciones entre sistemas productivo y cultural no se restrinjan a un país. La idea de una "literatura latinoamericana", por ejemplo, habla de la imposibilidad de trazar límites precisos. Por ejemplo, las manifestaciones del folclor no respetan fronteras políticas: pueden caracterizar regiones dentro de un país (no al país entero) o regiones que abarcan varios países. El ritmo de la política es diferente al del conjunto de la cultura; difícilmente se podrían hacer coincidir cultura y fronteras; por ejemplo, Colombia tiene formas de expresión cultural tan diversas como las del Llano, la Costa Atlántica y la zona Andina; sin embargo, sus características son comunes con regiones de Venezuela, el Caribe y Ecuador-Bolivia, respectivamente. Por las relaciones de 
sobredeterminación, puede afirmarse no sólo que la historia rige a la literatura, sino también que la literatura rige a la historia de la que hace parte; claro que habría que estudiar en qué medida en una sociedad específica: "una perspectiva artística puede modificar nuestra apreciación de la vida [...] la estética permite la creación de nuevas formas de sensibilidad ante la vida" (Londoño, 1989:73).

c. La literatura (así como las religiones más distintas y alejadas entre sí) muestra unas constantes más allá de los países, ya que los diversos pueblos, al pasar por necesidades materiales e intelectuales parecidas, recurren a instituciones y formas del pensamiento análogas (Lafargue, 1973:89). Por ejemplo, culturas tan alejadas en el espacio y el tiempo, como pueden serlo las orientales y las precolombinas, plantean experiencias esotéricas muy similares que se logran mediante mecanismos también similares (Cf. Bataille, 1979); no es novedoso, por ejemplo, el hecho de que un diluvio universal está presente en la tradición cultural de muchos pueblos distantes.

d. Para el psicoanálisis, el material psíquico que trabaja el escritor no es de su pertenencia: él maneja elementos que están presentes en todos los hombres y cuya simple comunicación causaría rechazo o, por lo menos, no podría procurar placer alguno; sin embargo, el trabajo poético los convierte en placenteros. De igual forma, el material mítico que maneja el escritor no le pertenece a su país, es patrimonio de la especie y refleja los patrones de posibilidad-condicionamiento psíquico del hombre. Los mitos, dice Freud (1974:18), corresponden a residuos deformados de fantasías optativas de la Humanidad joven; a su vez, la antropología los caracteriza co- mo papeles reguladoras de la sociedad, en el interior de una concepción de mundo.

e. Por último, según la semiótica del texto literario (Kristeva, 1978: 235-236), la literatura es escritura-réplica. O sea, la literatura es un diálogo con manifestaciones sociales que también vienen de otras latitudes, traducidas de otras lenguas, vistas desde diversas culturas. Nadie ha pensado desde una ingenua relación con el mundo objetivo, sino más bien como réplica a un mundo previamente interpretado.

Tenidas en cuenta estas características (literales a. hasta e.) ¿cómo hablar de valores artísticos "propios"? ¿Cómo saber lo que es y lo que no es "nuestro"? O, incluso, ¿para qué saberlo? Toda cultura es una hibridación. Toda literatura es, por definición, mestiza.

La idea de "unidad nacional" puede considerarse problemática. Por ejemplo, en nuestra Constitución se habla de respetar las diferencias, se reconoce la pluriculturalidad y, por otro lado, se plantea la unidad nacional. Históricamente, la posición dominante de los llamados a la "unidad nacional", a la "identidad" ha sido el privilegio de la unidad y el sacrificio de la diferencia. En principio, parece aceptable pensar que la unidad nacional se produce por la educación; pero si bien es cierto que la educación contribuye a producir ese efecto, también es cierto que no lo hace de manera deliberada, que no lo hace necesariamente en el sentido que se lo propone; es decir, que si a algo podemos llamarle "unidad nacional", no resulta del cumplimiento de determinados objetivos explícitos en el proceso educativo, entre otras cosas, porque entre los propósitos y la educación del país están las mediaciones sociales. La educación informal tal vez contribuye más a producir la "unidad nacional", salvo que, en relación con ella, los objetivos no son controlables con resoluciones. Grotescamente, el fanatismo futbolístico, el modelo de vida que pintan las propagandas, la telenovela de moda y las encuestas de opinión (para poner sólo unos ejemplos) son más forjadores de la "unidad nacional".

Mecanismos como la educación y el idioma oficial lo único que pretenden es reprimir la tendencia del hombre a ser una diáspora ${ }^{5}$, a nombre de una unidad nacional cuyo sentido, por un lado, es de naturaleza política y no representa nada que pudiéramos llamar identidad nacional; y, por otro, se constituye en un significante en relación con el cual los sujetos inscriben su habla (en otras palabras, es una ficción con efectos reales). Muy probablemente no es generalizable una educación con pretensiones de cultivar la diferencia y de denunciar el precio que se paga cuando se quiere luchar por la unidad, inexistente, pero que se constituye en una forma de desear, como decía Zuleta (1996: $10)$, que también produce segregación y violencia, en función de los mecanismos de las formaciones colectivas.

Hay una contradicción entre, de un lado, la jerarquización que hace MEN entre asignaturas importantes y asignaturas auxiliares (señalada en 1.1), y, de otro, el llamado a un aprecio por lo "propio". La razón de esta contradicción es que el criterio que determina la jerarquización tiene que ver con la supuesta validez universal del conocimiento científico, mientras que la cultura local está caracterizada justamente por lo provincial, por la validez local. Si se tratara de aplicar sistemáticamente el primer criterio, habría que desechar lo local, los "valores artísticos propios"; de tener en cuenta lo local y de aplicar sistemáticamente el criterio desde el que se sustentaría dicha petición habría que desechar la jerarquización.

\footnotetext{
5 Un análisis de este papel, jugado por la llamada "lengua nacional", está descrito exhaustivamente, para el caso de Francia, en Balibar y Laporte (1976).
} 


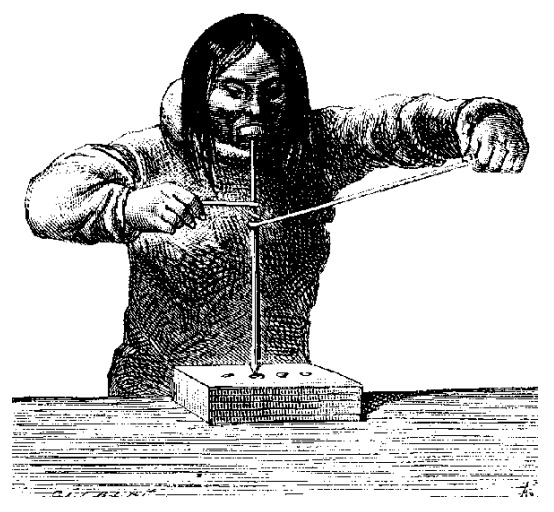

\subsection{El moralismo}

Otra forma -la última extra-literaria a la que nos referiremos- como el MEN justifica "ilegítimamente" la presencia de la literatura en primaria es por medio del moralismo. Por ejemplo, se dice que la enseñanza de los cuentos es importante «porque despierta el cariño por las personas, los animales y por todo aquello que rodea al niño. Además, por medio del cuento, el niño adquiere hábitos de higiene y de moralidad, aprende el verdadero sentido de la vida y enriquece su expresión con vocabulario adecuado» (3ํa:51).

Esta concepción es, obviamente, discutible en la medida en que el "cariño por las personas", por ejemplo, se produce fundamentalmente en la intersubjetividad, y ella marca la posición del lector frente a la interacción entre personajes de la literatura. Pues bien, semejante concepción tan problemática le permite al MEN introducir cuentos como $\mathrm{La}$ historia de Ricardo, cuyo comienzo dice: "Ricardo es un niño muy sano y fuerte; vive con sus padres en una casita en las afueras de la ciudad. Ricardo no está acostumbrado a usar letrina, y deposita sus heces cerca a los árboles. ¡Pobrecito, no sabe los daños que esto puede causarle!" (3ำ:185).

Aunque la utilización que se va a hacer de este cuento tiene que ver con el área de ciencias naturales ("Hacer un comentario de la lectura anterior y explicar brevemente los síntomas de la fiebre tifoidea [...]"), no puede negarse el tono moralista con el que una forma de vida es puesta como paradigma de ignorancia ("Si Ricardo tuviera un microscopio, podría observar algunos de los microbios y rechazaría el alimento, pero como no lo sabe, los ingiere con deleite"). Quien hace la caracterización le supone comportamientos al otro -se siente autorizado, pues se trata de un cuento, de una ficción-y luego los condena. Claro que si se sigue el paradigma de la ciencia occidental $^{6}$, todo vuelve a la normalidad: "Gracias al tratamiento oportuno al cual se sometió, Ricardo recuperó la salud". Es decir, la enfermedad es el castigo por no coincidir con el deber-ser materializado en la cartilla.

Cuentos así son perfectos estereotipos. Pese a esto, si el efecto fuera transformar positivamente los comportamientos del niño frente a la salud y al estudio, a expensas de la literatura, algo se habría logrado. No obstante, Bettelheim y Zelan (1983) encuentran que los niños terminan previendo lo que el maestro y la cartilla quieren y, en consecuencia, le hacen el juego a los ejercicios, pero ellos no ven allí algo que aporte para su vida. Para los niños, las historias de las cartillas sólo muestran niños y adultos, generalmente padres; ambos son presentados como seres insípidos; los personajes no muestran sentimientos verdaderos; las "grandes cosas" que supuestamente enseñan, ellos las saben mejor. Cuando se les preguntó por qué no lo habían expresado antes, comentaron que a nadie le importaba su opinión; que los maestros sólo esperaban respuestas del tipo "me gustó"; y que si las historias no eran sinceras, ¿cómo iban a exponer ellos opiniones así? (Ibid:24-25).

En este contexto, véanse los siguientes conceptos del MEN ( $3^{\circ} a: 52-$

\footnotetext{
6 Que, por otra parte, ya ha encontrado bastantes objeciones: Morin (1994) se refiere a él como "Uso degradado de la razón".
}

53): en los cuentos humorísticos: «debe procurarse que la jocosidad no caiga ni en lo vulgar ni en lo cruel»; en los cuentos realistas: «debe haber exaltación de las virtudes y reprobación de los vicios»; la norma de selección del cuento histórico y de aventuras: "se ajusta al valor de los hechos presentados, para fortalecer el carácter y despertar deseos de emulación de las hazañas nobles y generosas e ir comprendiendo el sentido de la vida". Ante esta forma de entender la literatura, vale la pena hacer dos comentarios:

a. Por una parte, es flagrante la siguiente contradicción: mientras en el Anexo / para tercero ( $3^{\circ} \mathrm{a}$.) se hacen tales recomendaciones, en el Desarrollo de los programas para el mismo curso (3ํㅡ.) nunca se manifiestan propósitos como esos; ni en los objetivos generales del área de Lenguaje, ni en los objetivos por cada unidad. Los objetivos generales nada buscan en relación con lo moral (no obstante el peso que esto gana en las actividades), ni con la literatura (hay que tener en cuenta que, sólo a partir de la Renovación Curricular, el área se denominó Español y $\mathrm{Li}$ teratura; antes se denominaba simplemente Lenguaje). Tal vez lo que produce la inversión entre propósitos explícitos e implícitos sea la particular articulación con los otros saberes, fundamentalmente sociales y naturales. El caso de segundo es tal vez más claro, pues el Desarrollo (2) no se da tanto por asignaturas como por semanas en las que aquellas se "integran"; este texto es de un marcado tono moralista en el que la utilización de la literatura privilegia la poesía-moraleja de rimas fáciles.

b. La función poética del lenguaje fue definida por Jakobson (1975: 358) como un énfasis en la materialidad del lenguaje, presente en todo enunciado; de ahí que incluso haya usado propagandas 
para ejemplificarla (:359). Esto evidenció que lo estético no es automáticamente artístico. De igual forma, el relato no constituye por sí mismo un valor estético ni confiere tampoco automáticamente el carácter de artístico. No obstante, es evidente que el MEN confunde el simple relato con el relato de carácter literario. De ahí que, entre los cuentos que utiliza para ejemplificar clases de cuentos, esté Alicia en el país de las maravillas al lado de El viaje de una gota de agua. El primero, un trabajo "desinteresado" aplicado sobre el lenguaje, los mitos y deseos humanos; mientras el segundo sólo busca explicar el ciclo del agua, como contenido de la clase de Ciencias Naturales.

Como en el caso de la propaganda -que, sin ser específicamente artística, hace un trabajo estético en busca de un efecto interpelativo-, de igual forma, el MEN pide utilizar el efecto estético del cuento y el interés por los relatos (sin que parezca entender la diferencia) para fines no artísticos. Un cuento utilizado en la escuela para despertar moralidad es un discurso moralista en un contexto didáctico, no literatura. Las conclusiones obtenidas a partir de la consideración del relato interesado, de contenidos "cognoscitivo" o moral, no pueden aplicarse a la literatura. Además, el imperativo moral que se quiere imponer al profesor carece de una aplicabilidad consecuente con el arte, no sólo por hacer de lado lo que el arte es, sino porque la petición, por un lado, está constituída de "opiniones" que ignoran el estado de la discusión ético-filosófica, y, por otro, no explicita sus principios. Por ejemplo, se pide al profesor que con el cuento enseñe "el verdadero sentido de la vida", lo que presupone que hay varios sentidos de la vida, entre los cuales uno es el verdadero. Pero, ¿cuáles son los otros? ¿Cómo distinguir el verdadero? Puede inferirse que quien plantea el asunto de esa forma tiene un referente absoluto que no sólo lo pone en el lugar de la autoridad, sino que hace incontrovertibles sus posiciones.

La pregunta por el sentido de la vida, que tal vez, en alguna medida, haya motivado las búsquedas cognoscitivas del hombre, no es una sola, ni permanece. Dos ejemplos: La biología moderna desplaza las respuestas por el sentido de la vida que involucran, desde fuera, "planes" y "finalidades" (Maturana y Varela, 1995: cap.II. Cf. también Monod, 1986; Schrödinger, 1983; Sagan y Druyan, 1993). Por su parte, la actual cosmología (Hawking, 1989: 222) establece que el universo es explicable sin recurrir a esas nociones.

La pregunta por el sentido de la vida estaría más relacionada con la realización de las potencialidades humanas. Por eso, aparecen ideas como las de Heidegger: el hombre es un proyecto; no está terminado sino que es pura temporalidad, atra-

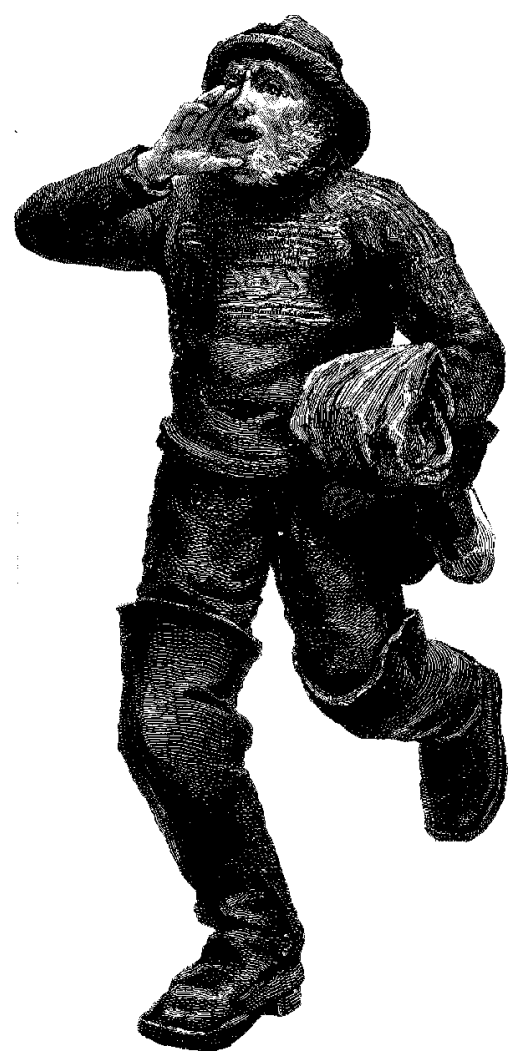

vesado constantemente por la muerte. Pero, ¿estaría la escuela dispuesta a lograr que el niño asuma la finitud, como sentido de la existencia? No; cuando el MEN habla de "sentido de la vida", se refiere a otra cosa. Por otra parte, los estudios acerca de las diversas culturas muestran que los proyectos humanos están históricamente determinados y, por lo tanto, son históricamente variables; o sea, que no se pueden elevar a la categoría de universales, que es lo presupuesto por la actitud moralista. Pero, ¿estaría la escuela dispuesta a lograr que el niño asuma la relatividad histórica de todos los principios sociales? No; cuando el MEN habla de "hábitos de moralidad", se refiere a otra cosa.

El panorama se complejiza cuando se mira hacia la especificidad de la literatura, pues ella bebe de la cotidianidad, de la ciencia y de la filosofía (aunque tales horizontes no le son específicos), y está inmersa en los valores culturales, escenifica tales valores; o sea, tiene que ver con "cariño", "higiene", "moral", "sentido de la vida", "virtudes", etc. (3a:51-52), pero no es moralizante 0 , mejor, no es edificante, como pretende el MEN, por ejemplo, con relatos como el siguiente: «Una linda niña jugaba con sus amiguitos en el jardín de su casa, el balón cayó a la calle y ella corrió tras de él; en su afán de alcanzarlo no tuvo en cuenta el semáforo y un carro la atropeIló; sus padres, muy afanados, llamaron al médico» $\left(2^{\circ}: 16\right)$.

La literatura no puede ser edificante porque le falta, a diferencia de otras instancias desde donde se profieren discursos, un referente absoluto ${ }^{7}$. Y, lo que es peor, como las actitudes no se generan exclusivamente en el ámbito del decir contextualizado escolarmente, puede que no sólo se esté atentando contra la

\footnotetext{
7 No es que haya referentes absolutos, sino que determinados ámbitos de discurso se amparan en esa suposición; lo cual les permite, hacia dentro, darse unidad y, hacia afuera, clasificar a los los sujetos.
} 
especificidad de la literatura, sino que tampoco se esté logrando el objetivo moralizante.

En la literatura aparecen posibles sentidos de la vida, pero no el sentido de la vida. Dos ejemplos: en la literatura de este siglo, se asume la vida como un absurdo (es el caso de El extranjero, de Albert Camus); en el arte griego, la existencia del hombre se asume trágicamente: está entre la obligación y los deseos, la autonomía humana y los dioses, la realización individual y la ciudad, el desenfreno y el control (es el caso de la Odisea); para los griegos, el sentido de la vida estaría dado por la perspectiva ética de la práctica de sí mismo, de la moderación, de la templanza; actitud que no tiene relación con el moralismo vertical que divide el mundo entre el bien y el mal.

Hoy florece una "ética discursiva", de tinte habermasiano, que podría definirse como el esfuerzo por explicitar y establecer concertadamente las condiciones pragmáticas de la comunicación (Mockus et al., 1994). En consecuencia, no habría referentes por fuera de las condiciones mismas de comunicación y en relación con los cuales las personas queden clasificadas como morales e inmorales; es decir, la caída de principios como los que el MEN ha expuesto expresamente y como los que subyacen a su ejercicio prescriptivo. Esta perspectiva ética es más parecida a la dialógica que señalara Bajtín (Cf. Bubnova, 1995); por su parte, Gadamer (1991) acuña la categoría de fiesta, similar a la bajtiniana de carnaval (Bajtin, 1987), para establecer una de las tres características que definen, para él, la especificidad de lo artístico. En otras palabras, antes que proponer una moral, la literatura pondría en acto un principio ético dialógico y, en consecuencia, abierto.

Por su parte, Lipovetsky (1986) plantea que hay tres momentos del pensamiento ético: inicialmente, un referente supuestamente exterior a los sucesos sociales (como los dioses, en la época clásica); enseguida, la razón como referente (durante la modernidad); y, finalmente, el sujeto mismo (que caracterizaría el momento actual). Esta clasificación -que señala la historicidad del asunto ético- también sirve para pensar una diacronía literaria: poesía heroica, que hacía honor a los principios transcendentes; literatura deconstructiva, que profundizó sobre lo social y lo anímico; y aliteratura, que propone un límite impreciso con el kitsch y con los géneros discursivos.

En conclusión, la literatura se define parcialmente por la escenificación de conflictos ético-morales en todas las épocas, pero no es un discurso moralista, aunque -por su complejidad y desdoblamiento virtual $^{8}$ - soporte lecturas que así la hagan ver. Quizá entre sus razones esté la siguiente paradoja: tanto la búsqueda siempre relativa de sentidos para la vida, como la contribución a interrogar por la existencia de un sentido para la vida.

\section{Justificaciones extra-literarias "legítimas"}

\subsection{La competencia comunicativa}

En la descripción que el MEN ( $3^{\circ} a: 51$ ) hace de la utilidad de la narración y del cuento, puede apreciarse la presencia de usos que ya tocan al lenguaje, que es la forma material de la literatura: «La narración es un medio eficaz para interesar a los niños en las diversas materias del programa escolar, a más del uso específi-

\footnotetext{
8 La narrativa literaria es una forma específica de articular los actos de significación y las condiciones sociales de su aparición: puede tener aseveraciones, predicciones e hipótesis, pero no es un discurso científico; puede tener requisiciones, compromisos, declaraciones y decisiones, pero no es un conjunto de enunciados sobre el funcionamiento social. Tiene expresiones afectivas e, incluso, puede ser una expresión afectiva, pero no se limita a expresar la necesidad afectiva de su autor o de los personajes.
}

co que de ella podemos hacer para desarrollar el poder de expresión de los alumnos [...] Además, por medio del cuento, el niño [...] enriquece su expresión con vocabulario adecuado». Nótese que la primera afirmación reconoce, tácitamente, que los otros usos, comentados antes (cf. punto 1), no tienen que ver con la especificidad de la literatura. El MEN invalida sus propios presupuestos.

EI MEN considera, pues, que el uso específico de la literatura, en la enseñanza primaria, está en relación con el poder de expresión y el enriquecimiento léxico; es decir, con aspectos que hacen parte de lo que podría denominarse competencia comunicativa. En otras palabras, se hace alusión a la especificidad del uso del cuento, pero se elude su materialidad: no importa qué es el cuento, sino para qué sirve. $Y$, aún así, no se comenta un posible "uso literario", sino uno extra-literario; otra vez la necesidad de una aplicación no artística, sino en un aspecto en el que se pueda obtener un resultado útil, incluso susceptible de ser medido, como puede ser el número de palabras nuevas en el vocabulario del niño.

De cualquier manera, se plantea una relación entre literatura y comunicación, bien sea en el sentido de la capacidad expresiva o de la adquisición de vocabulario, que es necesario comentar.

2.1.1. La competencia y el uso comunicativos son la columna vertebral de todo aprendizaje; una incompetencia en tal sentido perjudica no sólo la asignatura de lengua materna, sino todas las asignaturas. No obstante, para profesores que dictan todas las asignaturas (en los primeros años de la primaria) el poder expresivo de los estudiantes se cultiva en el momento en el que se esté haciendo el énfasis en lenguaje; $y$, para maestros que dictan "su" asignatura, la capacidad expresiva depende de otra asignatura: Español (o Lenguaje o Español y Litera- 
tura). En ninguno de los dos casos suele haber preguntas sobre la especificidad de los discursos que circulan en la escuela, sobre la labor esperable de ella frente a esas diferencias, sobre su posible desencuentro, sobre la existencia de formas comunicativas implícitas, sobre la jerarquización entre formas explícitas e implícitas.

La falsa separación entre momentos 0 asignaturas puede ser causa, al menos en forma parcial, de lo que se denomina "bajo rendimiento". Las ciencias Sociales y Naturales, como conocimientos que representan, también contribuyen a la capacidad verbal de los estudiantes y son asumidas por ellos en la medida de dicha capacidad; pero esto puede no ser "visible" si se piensa la especificidad de la escuela únicamente en el sentido de enunciar un conocimiento científico delante de un público que lo ignora (Cf. Not, 1994). Así, la pretensión de restringir el desarrollo de la competencia comunicativa a un momento o a una asignatura, otra vez escamotea la especificidad de la literatura; pero también le escamotea la especificidad discursiva a las asignaturas del currículo y a los espacios escolares.

En principio, puede ser cierto que la literatura incremente la capacidad verbal; pero poner eso como su razón de ser en la enseñanza es muy limitado, sobre todo cuando el MEN:

a. Le da importancia a aspectos como la posición corporal al escribir ( $\left.2^{\circ}: 29\right)$, o a la distancia del libro en relación con los ojos (1a:20); es decir, actitudes en las que se pone el deber-ser por encima de la construcción de significación y se olvida que es la función que busca satisfacerse con ayuda del lenguaje la que "corrige" posiciones y realiza el mejor "aprestamiento" conocido.

b. Enfatiza la entonación y la puntuación (3ำ:120); es decir, ejercicios en los que los contextos

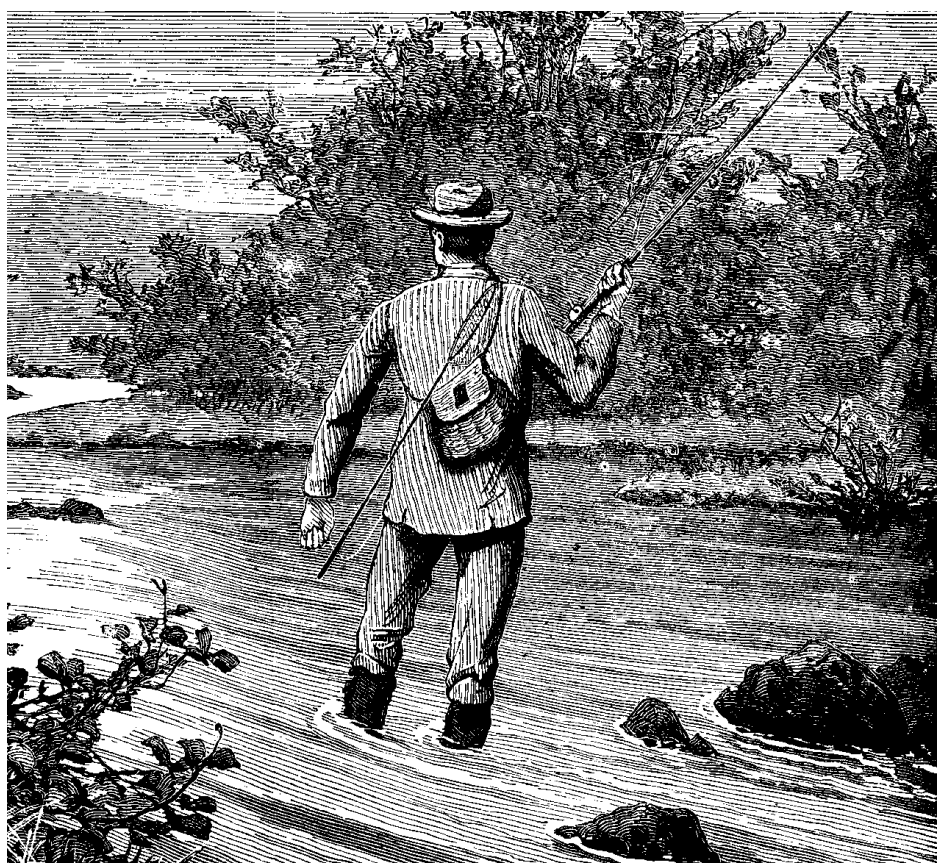

comunicativos no se toman como definitivos para determinar el sentido de sus aspectos constitutivos (como entonación y puntuación), y, en consecuencia, en los que se busca el ajuste a una norma.

c. Sugiere actividades de completación de frases (3ํํ:120, 196); es decir, ejercicios en los que los diálogos sobre los textos no se inscriben en conversaciones "auténticas", en las que no hay frases con huecos para completar, y en las que más bien aparece la anticipación, aplicada a lo que podría venir, de acuerdo con las probabilidades de aparición de los sonidos; con la forma como se rigen entre sí las palabras; con los contextos discursivo y comunicativo en los que aparecen las frases; con las competencias culturales que determinan los actos de habla. Al contrario, los ejercicios de completación de frases dadas se dirigen a lo dicho y materializan interacciones cuyo único sentido pragmático es tomar la lección. d. Usa las palabras de los textos con fines de enseñanza gramatical; es decir, ejercicios en los que, por una parte, la reflexión sobre estructura del lenguaje no es asumida como una cualificación de su uso, sino como una necesidad exigida desde fuera; $y$, por otra, en los que se extraen las palabras de su contexto para dar lugar a la máxima unidad de significación que este enfoque conoce: la frase. Por ejemplo: sacar la lista de sustantivos comunes y formar con ellos oraciones ( 2 : $: 93)$; formar oraciones con los nombres en diminutivo $\left(2^{\circ}: 125\right)$; sacar las palabras agudas y separar las que tienen tilde (3b:120); escribir sinónimos de expresiones y palabras de la lectura (3b:149); clasificar palabras según acentuación ( $3^{\circ} \mathrm{b}$ : 208); indicar el tiempo futuro de algunos verbos (3b:208).

e. Invita a hacer usos estereotipados de la lengua, tales como escribir tablas de precios de artículos del mercado como ejercicio, pero no hacer las compras ( ${ }^{\circ} \mathrm{b}: 97$ ); cartas que no van a ser 
realmente enviadas, pues son solicitadas por un personaje en un cuento (3ํํ:150); cartas que no se necesita enviar, porque se tiene al destinatario cerca $\left(3^{\circ} \mathrm{b}\right.$ : 196).

f. Sugiere escribir historias con palabras dadas; esto en primero es paradigmático y se aplica en pro de la ejercitación del vocabulario de la semana (1a:28, 32, 35, 45). Palabras como «Hermanito / Travesura / ¡Qué castigo!» (3ํb: 196) que, además, tienen una clara intención moralista. Como afirma Jurado (1992:43), ejercicios sin una lógica en la acción en los que se condiciona al niño a escribir desde la restringida perspectiva de la frase. Actividades formalmente parecidas pueden tener un sentido completamente distinto al buscado por el MEN: para Rodari (1992), por ejemplo, dar al niño dos palabras para que haga un relato, o agregar a un grupo de palabras ligadas por una historia previamente conocida, una palabra extraña, tiene como objetivo obligar a una palabra a descubrir su capacidad de crear nuevos significados (:21), o hacer reaccionar a las palabras usuales ante un nuevo contexto (:68).

g. Ordena diligenciar cuestionarios que sirven, o bien para hacer un resumen del cuento como consignación del tema (20:131; 3 ob:85), o bien para hacer "control de lectura" (1a:23, 67; $\left.1^{\circ} \mathrm{b}: 63,94,118 ; 2^{\circ}: 129 ; 3^{\circ} \mathrm{b}: 196\right)$. Es decir, en el primer caso, "ir llenando el cuaderno", sin tener en cuenta lo que hayan entendido los estudiantes del cuento como totalidad; se trata de hacer lecturas literales (donde no hay que inferir ni establecer presupuestos) y parciales (donde nunca se toma la macroestructura del texto) que, sumadas, van estableciendo la secuencia del cuento, tal como el profesor la reconstruyó, con el fin de dejar testimonio en el cuaderno de que

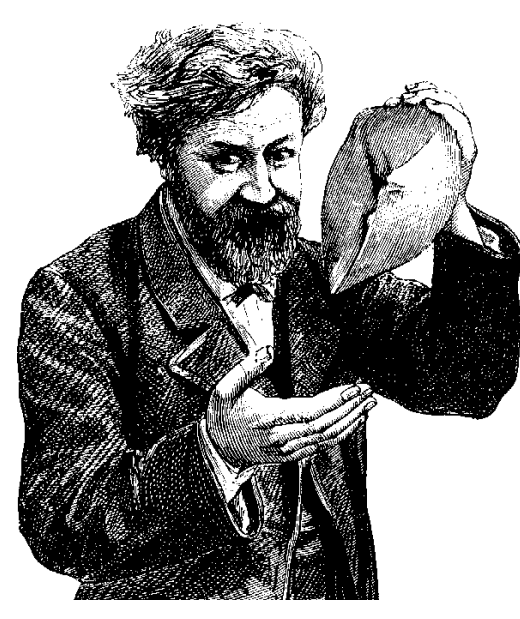

estudiantes del lado en el que "naturalmente" están, al que deberían estar. Esta posición se opone a la consideración del campo educativo como un objeto de investigación y del maestro como un sujeto que igualmente vive un proceso de aprendizaje; que son las actitudes que dieron lugar -para hacer referencia a un ejemplo del área que se analiza- a fructíferas investigaciones sobre el aprendizaje de la lectura y de la escritura ${ }^{9}$.

La posición del MEN autoriza al maestro de lengua materna a establecer uno de los usos lingüísticos como el modelo, frente al cual los otros pueden rechazarse, señalarse como "incultos", "inapropiados", característicos de gente "mal educada", "incorrectos", etc. Por ejemplo, uno de los objetivos de unidad en segundo $\left(2^{\circ}: 58\right)$ dice: «Comparar su escritura con la de un modelo y encontrar las fallas cometidas». Aquí, el modelo queda descartado como cometedor de fallas; éstas sólo pueden provenir del niño; de otro lado, el "error" es algo que se establece en relación con una norma y no en relación con las condiciones específicas del proceso comunicativo (donde muchos "errores" son funcionales y donde muchos usos canónicos son infuncionales). En realidad, el profesor raras veces está en posesión de la lengua normativa; él, como todo hablante, pertenece a una comunidad en la que los usos del lenguaje se dispersan en función de las diferencias sociales, de las actividades sociales. Ni siquiera el texto mismo del MEN está exento de usos anormativos e informales.

La oposición entre el modelo y las realizaciones de los niños, da lugar a que se hable de paso ordenado mente nifiesta el MEN en el ejemplo: señalar una línea divisoria entre lo bueno y lo malo a propósito del uso de la lengua, poner a la autoridad del lado bueno, a los estudiantes del lado malo (hasta que no demuestren lo contrario) y proponerse pasar a los
9 Investigaciones, como se sabe, iniciadas por Emilia Ferreiro. Esta investigadora, tanto como las personas que han colaborado con ella o seguido estudios independientemente, han partido de objetar dos evidencias: que el niño llega a la escuela sin saber leer ni escribir; y que el maestro ya domina dichas prácticas. 
(del principio al final) de las hojas (1a:20); mejorar la expresión oral $\left(2^{\circ}: 4\right)$; hacer la debida puntuación (:4); lograr articulación y entonación adecuadas (:12), o correctas (:54); utilizar con propiedad $(: 23,48,163)$ y escribir correctamente $(: 54,144$, 163) el nuevo vocabulario; mantener posición correcta al escribir (:29); usar correctamente singular y plural (:71); pronunciar correctamente el fonema $b$ en las unidades bra, bre, bla, ble... (:96); utilizar los términos apropiados (:101), el vocabulario adecuado, al hacer una descripción (120); identificar y usar adecuadamente los artículos y terminaciones de género (:114); emplear correctamente los diminutivos más usuales $(: 120)$.

Posiblemente el maestro no necesite una autorización para segregar usos de la lengua, pues la valoración del registro en el que hablan las personas suele ser usado socialmente para discriminar (Sttubs, 1984:22). Incluso podría plantearse que es esta perspectiva social la que hace presencia en la escuela, y no los objetivos escolares los que la producen.

Por estas razones, la asignatura de lenguaje se convierte en normativa, lo cual se opone al desarrollo de habilidades comunicativas, dando al traste con objetivos explícitos de la asignatura, tales como «mejorar la expresión oral mediante la coordinación de ideas en el relato de sus experiencias", en $2^{\circ}$; y estimular al niño para que adquiera «flexibilidad, riqueza y precisión en su lenguaje», y «confianza en sí mismo al expresarse", en $3^{\circ}$. Las disciplinas que estudian el funcionamiento social del lenguaje establecen que el uso determina las formas efectivas -en el sentido de funcionar de alguna manera para las intenciones del emisor- de uso de los signos para el contexto específico; esto hace que las mismas formas no tengan igual validez si se cambian de contexto (usar "términos científicos" -absolutamente pertinentes en su contexto- haría que un biólogo no tuviera éxito a la hora de contar chistes). Halliday (1982) es uno de los sociolingüistas que ha señalado esto y que hace propuestas pedagógicas consecuentes con ello.

De otro lado, una de las formas como se entiende la enseñanza es la de "dar" una nueva terminología a los estudiantes (Stubbs, 1984:13); cuando cada maestro dicta un área, su función puede ser entendida como enseñar la terminología de "su" disciplina. En esta perspectiva, es comprensible que el MEN postule con frecuencia objetivos, para el área de lenguaje, como los siguientes: para primero, las historias siempre se hacen para afianzar el vocabulario visto en la semana; para segundo, «utilizar el nuevo vocabulario» ( $\left.2^{\circ}: 23\right)$, «utilizar el vocabulario específico del tema» (:48), escribirlo (:54) correctamente (:76), incorporarlo (:58, 126, 148); y, para tercero, "ejercitarse en la escritura del vocabulario nuevo" (3b:28), «ampliar el vocabulario mediante la formación de familias de palabras» (:116), «aumentar el vocabulario científico, con los términos de la unidad» (:193). Es claro que no se entiende el aprendizaje como una capacidad operativa del sujeto y, en consecuencia, se siembra el terreno para un "aprendizaje" memorístico; es decir, para una respuesta del alumno coherente con el tipo de demanda que le hace la escuela.

Bettelheim y Zelan (1983:32) citan un estudio, realizado en los Estados Unidos, en el que, dada la falta de interés por la lectura y la calidad de la educación, siempre por debajo de lo esperado, el vocabulario de las cartillas se disminuyó paulatinamente, pues se creía que los problemas venían de la dificultad inherente a los textos. Se estableció que, de 1920 a 1962, el número de palabras usadas en las primeras cartillas de lectura bajó de 645 a 350 , siendo que los niños de primer grado con vocabulario "más reducido" manejan más de 2000 palabras (los hay que manejan hasta 4000). Por supuesto, «a medida que el número de palabras de cada historia y en todo el libro disminuía de edición en edición, el contenido se hacía más aburrido y repetitivo" (Idem). Las recomendaciones del MEN, pese a que dicen tratar de "enriquecer el vocabulario", lo hacen en el marco de la tendencia señalada por la investigación mencionada; enriquecer un vocabulario que no sea muy difícil, palabras que vayan en un orden de complejidad preestablecido y no determinado por las dificultades reales con los textos auténticos.

Por otra parte, la enseñanza del vocabulario de los cuentos ha sido, para segundo, una explicación de las palabras de "difícil significado" para luego emplearlas en oraciones sin funciones reales $\left(2^{\circ}: 122\right)$; o, para tercero, un ejercicio mecánico y estéril de búsqueda en el diccionario y construcción de frases igualmente de tablero: sacarlas de la unidad mayor de significación (el texto), en la que se definen por sus relaciones complejas, e introducirlas en unidades de significación parcial (la frase): «Leer cuentos, fábulas y otros textos relacionados con la unidad para buscar en el diccionario el significado de algunas palabras y emplearlas en oraciones" (3o:85). Después de leer «Los indios de nuestras tierras", los niños deben, entre otras actividades: «Buscar en el diccionario la significación de las palabras nuevas. Escribirlas y utilizarlas en oraciones. Formar con algunas, familias de palabras destacando la palabra primitiva y sus derivados» (3ํํ:149). Etc.

No es para sorpresas, entonces, que un tiempo después de las evaluaciones los estudiantes no recuerden el significado de palabras nuevas, ni hayan progresado en su uso verbal (o que pueda imputarse dicho progreso a los ejercicios de "fraseología" y no a la interacción entre niños, a la televisión, a la lectura misma, etc.). Para que el contacto con la literatura enriquezca la expresión de los estudiantes, la relación con el cuento tendría que ser vital y las palabras "nuevas" (así no sean "ade- 
cuadas") tendrían que integrarse a sus necesidades comunicativas reales $^{10}$.

\subsection{El uso estético del lenguaje}

La otra justificación extra-literaria "legítima" es la que se hace, en una alusión muy breve, por medio del uso estético del lenguaje. Según el MEN, cumpliendo algunas de sus recomendaciones (ya comentadas): «[...] se estimula al niño para que convierta su idioma, de utilitario, en instrumento de belleza» (3a:51). De este planteamiento se pueden hacer, al menos, cinco inferencias que es necesario comentar en aras de la aclaración de la especificidad de la literatura:

- El idioma puede concebirse por fuera de su uso.

- El idioma es fundamentalmente utilitario.

- Lo literario es una forma excepcional del idioma.

- La belleza caracteriza lo literario.

- Lo estético no es útil.

2.2.1. Que el idioma es algo concebible por fuera de su uso se deduce del hecho de que el MEN agregue a "lenguaje" el adjetivo "utilitario"; de lo contrario (es decir, concebir el lenguaje solamente en función de su utilización), la frase sería una redundancia. Desafortunadamente, la clase de lengua materna en la enseñanza básica se ha manejado con este presupuesto. De ahí que a los niños se les enseñe a leer y a escribir con frases artificiosas («la masa se amasa en la mesa») y con énfasis en aspectos formales y normativos, y no en relación con sus producciones reales, con sus capacidades intelectuales y comunica-

10 Esto se aplica también para los conocimientos de la gramática de la lengua en la primaria. No de otra forma podría entenderse el hecho de que, no obstante ver durante toda la primaria y la secundaria asignaturas correspondientes al área de lenguaje, la preocupación de que los estudiantes no saben leer ni escribir persiste aun en la universidad. tivas específicas y con su creatividad y emotividad. Esto es consecuente con las teorías que subyacen a dicha enseñanza y que, ante la alternativa del código o del uso, escogen el primero como su objeto de conocimiento. La gramática tradicional estaba muy preocupada por "cómo debe hablarse". De Saussure decía que sólo la lengua era sistemática y que en consecuencia sólo ella podía ser objeto de conocimiento de una ciencia. Y, por su parte, Chomsky tomó como objeto de estudio la competencia de un hablante-oyente ideal. Desde lo que se viene comentando, las tres posiciones son idénticas. En este panorama, la enseñanza de la literatura sería un medio privilegiado para vincular los aspectos creativo y emotivo del niño.

2.2.2. Que el idioma es fundamentalmente utilitario lo presupone el MEN al postular su convertibilidad en instrumento de belleza, pues el estado que debe ser transformado es el más usual, incluso el constitutivo. Afirmar tal cosa depende de establecer qué se entiende por "utilitario". Evidentemente el lenguaje es un logro de la especie humana con finalidades específicas: se creó para ser utilizado y existe gracias a que se utiliza: "La lengua es como es a causa de las funciones que ha desarrollado para servir en la vida de la gente» (Halliday, 1982:13). Pero ¿cuáles son esas finalidades? En este punto los autores no se ponen de acuerdo (cf. Bühler, Jakobson, Halliday, Baena) aunque se señalan con mayor o menor consenso, usos socializante, subjetivante, emotivo, interpelativo, interaccional, cognoscitivo, referencial, poético, fático y metalingüístico.

En tal sentido, pues, el lenguaje sería utilitario; se definiría en gran parte por ese aspecto. Pero, si se entiende "utilitario" como aquello aplicable más o menos en forma inmediata para obtener algún tipo de ganancia, el criterio resulta más impreciso. Por ello se diferenciaron, en 1.1, prácticas sociales "desinte- resadas" / "interesadas"; pero, como tal vez esta clasificación responde más a apariencias, podría caracterizarse mejor como prácticas con un "interés socialformativo" (ciencia, filosofía, arte) y prácticas con "interés de aplicación inmediata" (técnica, enseñanza, comercio).

En la escuela, es necesario concebir la capacidad de reflexionar y de recrear la realidad como constitutivas del hombre; y al uso del lenguaje, en cualquiera de estos sentidos, como parte de sus funciones constitutivas. Los estudios sobre diversas comunidades parecen arrojar cada vez más evidencia sobre el hecho de que la simbolización constituye al hombre y que la determinación económica (que, en últimas tanto preocupa a la educación) pasa por esta simbolización; o sea, que no habría determinismo económico a ultranza.

2.2.3. Que lo literario es una utilización excepcional del idioma se desprende de la segunda concepción de utilitario (la utilizada por el MEN) y de que se invite a "convertir" el lenguaje en instrumento de belleza, es decir, en lenguaje literario. Tal

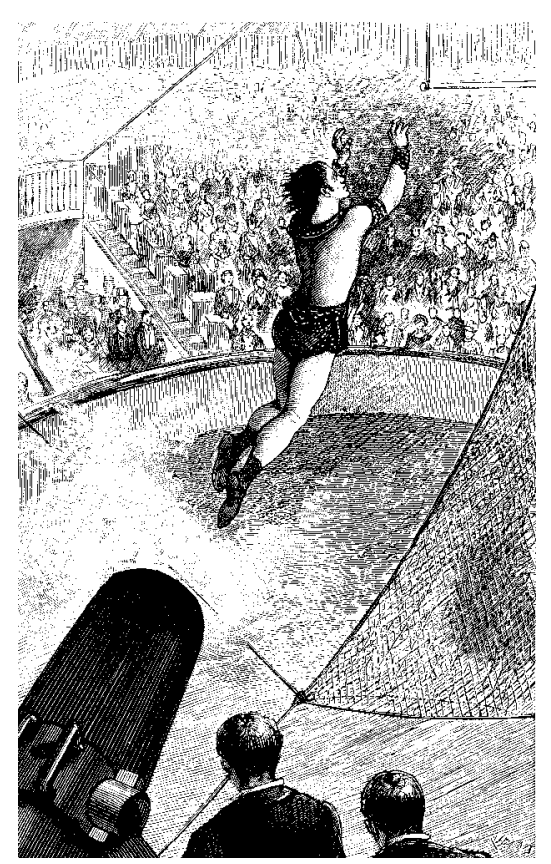


idea conlleva a pensar a la literatura ( $y$ al arte, en general) como una esfera aislada de la sociedad, y a sus factuores como una élite especial, también en cierta forma aislada de la sociedad. Se termina pensando que el arte no sería para todos y que hacerlo depende de poseer la clave de la "creación". Es decir, se omite el proceso productivo del arte y se lo asimila a las prácticas interesadas; y como no se lo conoce pero se propagandea su necesidad, entonces hay que "consumirlo" (comprarlo y acumularlo para ser personas "cultas"), pero no producirlo, eso sería para genios; o, en último caso, entrar a una institución "autorizada" para enseñarlo; y tampoco problematizar con él la vida, se trata de disfrutarlo como se disfruta un cigarrillo.

Como resultado, puede contribuírse al debilitamiento de las prácticas culturales de las comunidades (trova, poesía, declamación, relato, danza, música, etc.) -pese a la resistencia que ellas ejercen-, así como de las posibles prácticas culturales individuales, en pro de la comercialización de la cultura, de la especialización en actividades "útiles" y de la elitización de la cultura.

Sin embargo, la diferencia entre "idioma utilitario" e "idioma para la belleza" es relativa: la lingüística ha encontrado que el lenguaje "denotativo" que parece apuntar hacia las cosas ("utilitario", en términos del MEN), pasa también por el consenso, como el "connotativo"; o sea que es convencional como aquel que recrea el sentido del mundo ("para la belleza", en términos del MEN). También se plantea que el efecto de denotación es un efecto connotativo: «La denotación no es el primero de los sentidos, pero finge serlo; bajo esta ilusión no es finalmente sino la última de las connotaciones» (Barthes, 1987:6); en otras palabras, que el lenguaje cotidiano tiene características de lenguaje literario y viceversa (Dubois et al., 1979:139). Entonces, no es cierto que se estimule al niño «para que convierta su idio- ma, de utilitario, en instrumento de belleza», como dice el mEN, pues las propiedades estéticas ya están en el lenguaje.

2.2.4. Que la belleza caracteriza lo literario se deduce de la noción de "belleza" utilizada por el MEN para referirse a la literatura: el concepto básico de la estética tradicional. Esta noción inmediata acerca de lo "bello" podría objetarse fácilmente: entre los mismos productos "reconocidos" como arte se encuentran algunos mutuamente excluyentes, o ejemplares que están en oposición radical con algunos principios sociales de belleza. Los educandos mismos entienden que esta noción es relativa, pues lo que a alguien parece bello, a otro puede no parecerle.

Desde los filósofos griegos (por ejemplo, en el diálogo Hipias mayor o de lo bello de Platón) tal concepto se ha caracterizado por su inexactitud y su adaptabilidad a muchos criterios y objetos, es decir, por su relatividad cultural. La tarea sería un análisis riguroso de la literatura, con ayuda de la filosofía (estética) y de disciplinas como el materialismo histórico (cuando se refiere al efecto artístico), el psicoanálisis (en su estudio del goce estético ${ }^{11}$ y la lingüística (más exactamente, la poética).

\subsubsection{La idea de que lo estético no} es útil se deduce de que el MEN proponga convertir el lenguaje utilitario en otra cosa que, por lo mismo, no será útil: lo estético. Esta idea, tan relevante en la educación colombiana, conduce a la percepción de las materias humanísticas (entre las que está la literatura) como meras "costuras", es decir, secundarias, de relleno, y las demás como importantes.

\footnotetext{
11 Son clásicos los estudios de Freud sobre literatura; por ejemplo, sobre autores como Dostoyevski, Shakespeare, Goethe, Jensen. Por su parte, Kofman (1973) hace un recorrido por los análisis psicoanalíticos de obras artísticas, pues no hubo una teoría específica de Freud al respecto.
}

En los textos estudiados del MEN es evidente que no se «estimula al niño para que convierta su idioma, de utilitario, en instrumento de belleza", como él mismo dice ( $\left.3^{\circ} a: 51\right)$. Desde un comienzo, la labor era imposible, pues la palabra del niño queda por fuera de consideración cuando se tiene una idea normativa del lenguaje y de su enseñanza. La estética del lenguaje, presente en todos sus usos, queda descartada cuando se piensa que lo estético es un uso deliberado y presente sólo en ciertas formas canónicamente reconocidas como tales. La belleza, como definición de una propiedad especial de la literatura, queda ahogada en la especificidad de los textos edificantes (en sentido cognitivo o moral) que se le presentan al niño $y$ con los que se lo hace trabajar, que no tienen belleza alguna y que, desde el punto de vista de la significación, más bien son obvios, y que, desde el punto de vista formal, no ofrecen alternativas al uso cotidiano del lenguaje.

Un último aspecto que podría estar relacionado con el llamado "uso estético" del lenguaje es la parte lúdica (hay concepciones que relacionan la especificidad de la literatura con este aspecto). Curiosamente, la "lectura recreativa" se menciona apenas en primero, en tres ocasiones $\left(1^{\circ} \mathrm{a}\right.$ : $61,66,72$ ), como objetivos; no obstante, en el desarrollo no se lleva nada a cabo al respecto; a no ser una "libre" interpretación de dos poesías -cuyo tema es el tema central de la semana ( $\left.1^{\circ} \mathrm{b}: 119\right)$ - o la lectura de unos relatos-jeroglíficos (:120).

\section{Bibliografía}

Arboleda, Rubén. "Sobre la Reforma Curricular: el caso de Español y Literatura". En: Revista .Colombiana de Educación № 18. Bogotá: Universidad Pedagógica Nacional, Il semestre de 1986.

Baena, Luis Ángel y Bustamante, Guillermo. "El área de lenguaje y el rendimiento escola". En: Revista La Palabra № 1. Tunja, UPTC, 1993. 
BAJTín, Mijail. La cultura popular en la Edad Media y el Renacimiento. Madrid: Alianza, 1987.

BALIBAR, Etienne y LAPORTE, Dominique. Burguesía y lengua nacional. Barcelona: Avance, 1976.

Barthes, Roland. Leçon. Paris: Du seuil, 1978.

S/Z. Madrid: Siglo XXI, 1987.

BatAllle, Georges. La experiencia interior. Madrid: Taurus, 1979.

Bettelheim, Bruno y Zelan, Karen. Aprender a leer. Barcelona: Grijalbo, 1983.

Bubnova, Tatiana. "El principio ético como fundamento del dialogismo en M. Bajtín". En: Revista La Palabra № 4-5, 1995.

Bustamante, Guillermo."Competencia comunicativa y enseñanza de la lengua materna". En: Cuadernos de Lingüística No. 3. Tunja, UPTC, 1990.

"Introducción al análisis de la Reforma Curricular en el área de lenguaje". En: revista Enunciación № 1. Bogotá: Universidad Distrital, julio de 1996.

Dubols, Jean et al. Diccionario de Lingüística. Madrid: Alianza, 1979.

FREUD, Sigmund. "El poeta y la fantasía". En: Psicoanálisis aplicado y técnica psicoanalítica. Madrid: Alianza, 1974.

GadAmer, Hans-Georg. La actualidad de lo bello. Barcelona: Paidós, 1991.

GRISOLLE, Juan. La creación literaria en los niños. Bogotá: Ecoe, 1991.

HaLLIDAY, M.A.K. El lenguaje como semiótica social. México: Fondo de Cultura Económica, 1982.

Hawking, Stephen. Historia del tiempo. Barcelona: Crítica, 1989.

JAKOBSON, Roman. "Lingüística y poética". En: Ensayos de lingüística general. Barcelona: Seix Barral, 1975.

JURADo, Fabio. "La escritura: proceso semiótico reestructurador de la concien- cia”. En: Revista Forma y Función № 6 . Bogotá: Universidad Nacional, Abril de 1992.

Kofman, Sarah. El nacimiento del arte. Buenos Aires: Siglo XXI, 1973.

KRISTEVA, Julia. Semiótica. Madrid: Fundamentos, 1978.

Lafargue, Paul. "El método histórico". En: El materialismo histórico según los grandes marxistas. México: Roca, 1973.

LiPOVETSKy, Gilles. La era del vacío. BarceIona: Anagrama, 1986.

LONDOÑo, Carlos Arturo. "La formación del sujeto reflexivo". En: Revista Inquietud empresarial. Vol. 2, No. 2. Tunja, UPTC, 1989. . "El sentido del arte". En: Estanislao Zuleta 1935-1990. Tunja: La Rana y el Aguila, 1990.

Maturana, Humberto y Varela, Francisco. De máquinas y seres vivos. Santiago de Chile: Universitaria, 1995.

Ministerio de Educación Nacional (men). Guía para el maestro. Primer grado de enseñanza primaria. Parcelación. Bogotá: MEN, 1975a.

. Guía para el maestro. Primer grado de enseñanza primaria. Desarrollo. Bogotá: MEN, 1975b.

. Guía para el maestro. Segundo grado de enseñanza primaria. Desarrollo. Bogotá: Italgraf, 1972a.

Guía para el maestro. Tercer grado de enseñanza primaria. Anexo I. Bogotá: Italgraf, 1972b.

. Guía para el maestro. Tercer grado de enseñanza primaria. Desarrollo. Bogotá: Italgraf, 1972c.

. Marcos Generales de la Renovación Curricular. Bogotá: MEN, 1984.

Saber. Sistema Nacional de evaluación de la calidad de la evaluación. Primeros resultados: matemáticas y lenguaje en la básica primaria. Bogotá: MEN, 1992.
Mockus, Antanas et al. Las fronteras de la escuela. Bogotá: Sociedad Colombiana de Pedagogía, 1994.

MonOD, Jacques. El azar y la necesidad. Barcelona: Orbis, 1986.

MoRIN, Édgar. Introducción al pensamiento complejo. Barcelona: Gedisa, 1994.

Not, Louis. Las pedagogías del conocimiento. Bogotá: Fondo de Cultura Económica, 1994.

Rincón, Gloria et al. "La lengua materna en la escuela y la Reforma Curricular". En: Revista Educación y Cultura № 9. Bogotá: FECODE, Septiembre de 1986.

RodARI, Gianni. Gramática de la Fantasía. Barcelona: Ferrán Pelissa, 1992.

Sagan, Carl y Druyan, Ann. Sombras de antepasados olvidados. Barcelona: Planeta, 1993.

SCHRÖDINGER, Erwin. ¿Qué es la vida? Barcelona: Tusquets, 1983.

StuBBS, Michael. Lenguaje y escuela. Madrid: Cincel-Kapelusz, 1984.

Todorov, Tzvetan. "Las categorías del relato literario". En: Análisis estructural del relato (varios autores). Buenos Aires: Tiempo Contemporáneo, 1970.

y Ducrot, Oswald. Diccionario enciclopédico de las ciencias del lenguaje. Buenos Aires: Siglo XXI, 1975.

VAsconi, Tomás. Ideología, lucha de clases y aparatos educativos en el desarrollo de América Latina. Bogotá: Latina, 1975.

ZuletA, Estanislao. Arte y filosofía. Medellín: Percepción, 1986.

"Elogio de la dificultad". En: Elogio de la dificultad y otros ensayos. Cali: Fundacíon EZ, 1996. 